\title{
Temporal Dynamics of Stomatal Conductance of Plants under Water Deficit: Can Homeostasis be Improved by More Complex Dynamics?
}

\author{
Gustavo Maia Souza ${ }^{1 *}$, Ricardo Ferraz de Oliveira ${ }^{1}$ and Victor José Mendes Cardoso ${ }^{2}$ \\ ${ }^{I}$ Departamento de Ciências Biológicas; ESALQ/USP; gumaia@universiabrasil.net; C. P. 9; 13418-900; Piracicaba - \\ SP - Brazil. ${ }^{2}$ Departamento de Botânica; UNESP; Rio Claro - SP - Brazil
}

\begin{abstract}
In this study we hypothesized that chaotic or complex behavior of stomatal conductance could improve plant homeostasis after water deficit. Stomatal conductance of sunflower and sugar beet leaves was measured in plants grown either daily irrigation or under water deficit using an infrared gas analyzer. All measurements were performed under controlled environmental conditions. In order to measure a consistent time series, data were scored with time intervals of 20 s during 6 . Lyapunov exponents, fractal dimensions, KS entropy and relative LZ complexity were calculated. Stomatal conductance in both irrigated and non-irrigated plants was chaotic-like. Plants under water deficit showed a trend to a more complex behaviour, mainly in sunflower that showed better homeostasis than in sugar beet. Some biological implications are discussed.
\end{abstract}

Key words: Beta vulgaris, complexity, Helianthus annus, stability, time series analyses, water deficit

\section{INTRODUCTION}

Plants like other living beings are open systems able to have material and energetical exchanges with the environment. Only under conditions of continual exchange with the environment can organisms be maintained in a state far from their thermodynamic equilibrium. The plants maintain themselves under low entropy conditions, a necessary prerequisite to life (Ksenzhek and Volkov, 1998). Stomata are the main path for higher plants to exchange matter and energy with their environment. Stomata may respond homogeneously for heterogeneously to environmental conditions. By varying the width of the stomatal pores plants are able to control the flux of $\mathrm{CO}_{2}$ and $\mathrm{H}_{2} \mathrm{O}$ between the leaf and the surround air in response to changes in environmental factors. However, not all leaf stomata are open at the same time at a particular moment. This behavior is named patchy stomatal closure, in which stomata of different locations on the leaf show different responses to similar perturbations (Terashima, 1992; Larcher, 1995; Mott et al., 1997; Haefner et al., 1997). According to Cardon et al. (1994), during strong oscillatory behavior or even at a steady-state stomatal conductance, a surprising number of different behaviors in the dynamics of the photosynthetic activity may be found.

Biological systems from the molecular to the ecological level are often controlled by non-linear feedback mechanisms. It is not surprising that these mechanisms are responsible for unusual

\footnotetext{
* Author for correspondence
} 
behaviors, such as the chaotic ones (May, 1989; Mosekild and Mosekild, 1991). Broadly, chaotic dynamics is largely unpredictable long-term evolution occurring in a deterministic, nonlinear dynamical system because of sensitivity to initial conditions (Williams, 1997). Some authors have observed chaotic dynamics in plants in different physiological processes. Lüttge and Beck (1992) showed the possible existence of chaotic dynamics in endogenous rhythms in certain CAM species. Krempaský et al. (1993) indicated that varying light intensities caused changes in the patterns of photosynthetic temporal behaviors, ranging from periodic to chaotic behavior. Shabala et al. (1997) observed period-doubling and period-tripling in higher plants, which suggested two different routes to chaos in leaf temperature responses of maize, tomato, and burweed plants.

Although the stomatal response to the environment involves complex mechanisms influenced by many factors, stomatal movements appear to be governed by two principal control circuits, one involving gradients of $\mathrm{CO}_{2}$ and the other involving gradients of $\mathrm{H}_{2} \mathrm{O}$ vapor. Patchwise stomatal closure is especially pronounced under stress situations, such as water deficit (Terashima et al., 1988; Larcher, 1995).

We supposed that leaf stomatal conductance, as an ubiquitous and fundamental process in higher plants, need to be stable (in a Lyapunov sense, see Fiedler-Ferrara and Prado, 1994) to allow plant adaptation to environmental changes. Stability in biological systems is related to homeostatic capacity. According to Kauffman (1993), homeostasis is the system ability to return to its normal condition after an environmental disturbance.

According to Peixoto's Theorem (Fiedler-Ferrara and Prado, 1994) systems with chaotic dynamics are more stable when disturbed by external factors. Thus, in this study, we hypothesized that leaf stomatal conductance could have a chaotic-like behavior under different water regimes.

\section{MATERIALS AND METHODS}

Measurements of stomatal conductance were made on 60-d old plants of sugar beet (Beta vulgaris) and sunflower (Helianthus annus). Seeds were sown directly into pots containing $5 \mathrm{~kg}$ of organic matter (Plantmax, Eucatex agro). Plants were grown in a greenhouse. Modified Hoagland's nutrient solution (McCree, 1986) $\mathrm{pH} 5.9$ was used for both the species. Two water regimes were used: daily irrigation and water deficit. For water deficit treatment, irrigation was suspended for 6 consecutive days, when measurements were taken for: stomatal conductance $\left(g_{s}, \mathrm{~mol} \mathrm{~m} \mathrm{~m}^{-2}\right)$, net photosynthesis rate $\left(\mathrm{A}, \mu \mathrm{mol} \mathrm{m} \mathrm{s}^{-1}\right)$, intercellular $\mathrm{CO}_{2}$ concentration $\left(\mathrm{Ci}, \mu \mathrm{mol} \mathrm{mol}{ }^{-1}\right)$ and water use efficiency (WUE, $\mu \mathrm{mol} \mathrm{CO} \mathrm{Cmol}^{-1} \mathrm{H}_{2} \mathrm{O}$ ). The WUE was estimated by the relation between $\mathrm{A}$ and $\mathrm{E}$ (transpiration rate): WUE $=\mathrm{A} / \mathrm{E}$. Afterwards, the plants under water deficit were irrigated and new measurements in the same leaves were taken in order to verify the homeostatic capacity of plants after $12 \mathrm{~h}$ of recovery. Leaf water potential $\left(\Psi_{\mathrm{w}}\right)$ was measured in both treatments in the beginning of gas exchanges measurements. $\Psi_{\mathrm{w}}$ was measured psychrometrically by a dew-point microvoltmeter device (model HR 33T, WESCOR, Logan, Utah, USA) attached to a sample chamber model C-52 (WESCOR) at $25^{\circ} \mathrm{C}$.

A portable gas exchange system (model LI-6400, Li-Cor, Lincoln, NE, USA) was used to measure $\mathrm{g}_{\mathrm{s}}, \mathrm{A}, \mathrm{E}$ and $\mathrm{Ci}$. Measurements were taken inside of a phytotron (model E15, Conviron, Winnipeg, Canada) to ensure that the plant responses were due only to plant internal dynamics, with minimal environmental noise. The plants were placed inside the phytotron one-day before the measurements to allow the plant acclimation. According to Buckley et al. (1997), we supposed minimal stomatal heterogeneity effects on gas exchange measurements. Furthermore, the noise of the measurements (Pearcy et al., 1989) was evaluated with the empty chamber sampling. This test showed that the noise due to the LI-6400 was very low $\left(<2 \%\right.$ for $\mathrm{A}$ and $<0,005 \%$ for $\left.\mathrm{g}_{\mathrm{s}}\right)$ and could be set aside (Souza et al., 2001). Total exponent of variation (total CV\%) of the LI-6400 was between 0.0 and $0.2 \%$ during the measurements. These results were in accordance with the specifications showed in the LI-6400 User Guide (noise for $\mathrm{CO}_{2}$ was $0.2 \mu \mathrm{mol} \mathrm{mol}{ }^{-1}$ and 0.04 mmol $\mathrm{mol}^{-1}$ for $\mathrm{H}_{2} \mathrm{O}$ ). Furthermore, the LI-6400 took new measures every 0.75 seconds, which was suitable for the time interval used in this study (20 seconds). The measurement conditions were: $400 \mu \mathrm{mol} \mathrm{mol}^{-1} \mathrm{CO}_{2}, 25^{\circ} \mathrm{C}$ (inside sample chamber and phytotron), and $1400 \mu \mathrm{mol} \mathrm{m} \mathrm{m}^{-2} \mathrm{~s}^{-1}$ of PPFD (photosynthetic photon flux density). The data were taken during 6 consecutive hours at intervals of 20 seconds. The measurements were performed 
at the third fully unfolding leaf from plant apex in three different plants of each species. The leaf area sampled per plant was $6 \mathrm{~cm}^{2}$.

Lyapunov exponent $\gamma$ (largest one), KolmogorovSinai entropy KS, capacity and correlation dimensions, and relative LZ complexity were calculated to analyze the temporal dynamics of stomatal conductance. The analysis were done using the Chaos Data Analyzer (CDA) software (version 2.1, Physics Academic Software, Raleigh, NC, USA). Before the analysis, when necessary, the steady-state of data was acquired by the differencing method (first difference), in order to remove non-stationary factors. The CDA software allows determining an appropriate embedding dimension in order to reconstruct the dynamics according to Takens (1981). In this study a threedimensional dynamic reconstruction with lag two was used.

The Lyapunov exponent estimates the rate at which similar trajectories in phase space diverge. The exponent should be zero or negative for periodic data, positive for chaotic data, and infinite for uncorrelated random data. KS entropy is a measure of the disorder in the data. The relative LZ complexity is a measure of the algorithmic complexity of the time series, in which maximal complexity (randomness) has a value of 1.0, and perfect predictability has a value of 0 . Algorithmic complexity accounts to the size of the all concise system description (Sprott and Rowlands, 1995; Gell-Mann 1996; Williams 1997).

Chaotic behavior is characterized by show at least one Lyapunov exponent $>0$, KS entropy finite and $>0$, and low fractal dimensions (capacity and correlation). Correlation and capacity dimensions greater than 5.0 implies random data (Çambel 1993; Fieddler-Ferrara and Prado 1994; Sprott and Rowlands 1995). However, according to Poon and Barahona (2001), the Lyapunov exponent estimation in experimental time series can be very sensible to measurement noise, which could make the determination of chaotic behavior not reliable. Thus, once the measurement noise must be present in all data taken, we considered the mathematical parameters as complexity index rather than a chaotic reliable index.

\section{RESULTS}

Leaf water potential of irrigated plants were - 0.46 $\mathrm{MPa}$ and $-0.69 \mathrm{MPa}$ for sunflower and sugar beet, respectively. For non-irrigated plants, these values ranged from $-2.44 \mathrm{MPa}$ in sunflower to -2.25 $\mathrm{MPa}$ in sugar beet. The water deficit reduced $\mathrm{g}_{\mathrm{s}}$ in both sunflower and sugar beet, decreasing $\mathrm{Ci}$ and A values. For both species, water use efficiency (WUE) increased, mainly in sugar beet. However, WUE in sunflower was higher than in sugar beet in well-watered and drought conditions (Table 1). $\mathrm{g}_{\mathrm{s}}$ and $\mathrm{A}$ values recovered faster in sunflower than in sugar beet showing the highest homeostatic capacity of the former. Vapor pressure deficit (VPD) in sample chamber increased when the plants were under water deficit conditions (from 1.04 to $1.79 \mathrm{KPa}$ for sunflower and from 0.68 to $1.68 \mathrm{KPa}$ for sugar beet). Since plants were inside a phytotron, in an environmental controlled room at same temperature $\left(25^{\circ} \mathrm{C}\right)$, we considered that changes in the VPD values inside of the sample chamber might be accounted by the plant water status. Furthermore, VPD mean showed small standard deviations during time series measurements (Table 1).

The results of $g_{s}$ time series analyses (Table 2) suggested a chaotic-like behavior in all treatments. All series analyses showed positive Lyapunov exponents and $\mathrm{K}$ entropy finite and positive. In all analyses performed, fractal dimensions (capacity and correlation) were less than 5 reinforcing the presence of deterministic chaos in $\mathrm{g}_{\mathrm{s}}$ time series. According to relative LZ complexity results, there was a trend to a higher complexity in $g_{s}$ behavior for both plants under water deficit conditions, but mainly in sunflower. The higher value of KS in irrigated sunflower supported the observation of a more complex behavior than in sugar beet (Table 2).

Dynamics of $g_{s}$ time series, as shown in Figs. 1 (sunflower) and 2 (sugar beet), made clear the irregularity of $g_{s}$ behavior. 
Table 1: Stomatal conductance $\left(\mathrm{g}_{\mathrm{s}}, \mathrm{mol} \mathrm{m} \mathrm{m}^{-2}\right)$, intercellular $\mathrm{CO}_{2}$ concentration $\left(\mathbf{C i}, \mu \mathrm{mol} \mathrm{mol}^{-1}\right)$, net photosynthesis rate $\left(\mathbf{A}, \mu \mathrm{mol} \mathrm{m} \mathrm{m}^{-1}\right)$, vapor pressure deficit in sample chamber (VPD, KPa), water use efficiency $(\mathbf{W U E}, \mu \mathrm{mol} \mathrm{CO} 2$ $\mathrm{mmol}^{-1} \mathrm{H}_{2} \mathrm{O}$ ) of sunflower (Helianthus annus) and sugar beet (Beta vulgaris) irrigated and under water deficit $( \pm \mathrm{SD})$.

\begin{tabular}{cccccccccc}
\hline Treatment & $\mathbf{g}_{\mathbf{s}}$ & $\mathbf{A}$ & $\mathbf{C i}$ & $\mathbf{V P D}$ & WUE & $\mathbf{g}_{\mathbf{s}}$ (rec.)\# & $\mathbf{A}(\mathbf{r e c}) \#$ \\
\hline Irrigated sunflower & $0.36 \pm 0.09$ & $28.92 \pm 1.5$ & $262.99 \pm 4.4$ & $1.04 \pm 0.01$ & 4.23 & $0.35 \pm 0.06$ & $21.50 \pm 3.4$ \\
Droughted sunflower & $0.16 \pm 0.03$ & $14.77 \pm 2.2$ & $218.97 \pm 14.1$ & $1.79 \pm 0.04$ & 5.18 & - & - \\
Irrigated sugar beet & $0.32 \pm 0.09$ & $29.42 \pm 0.8$ & $327.1 \pm 3.23$ & $0.681 \pm 0.01$ & 2.87 & $0.26 \pm 0.07$ & $17.32 \pm 0.8$ \\
Droughted sugar beet & $0.12 \pm 0.02$ & $17.5 \pm 1.6$ & $227.98 \pm 9.3$ & $1.676 \pm 0.05$ & 4.37 & - & - \\
\hline
\end{tabular}

\#Data taken 12 hours after irrigation of droughted plants (recovery)

Table 2 - Time series analysis of the stomatal conductance dynamics (largest Lyapunov exponents $\lambda$, KolmogorovSinai entropy $\mathbf{K S}$, correlation $\mathbf{D}_{\text {cor }}$, capacity dimension $\mathbf{D}_{\mathbf{0}}$, and relative $\mathbf{L Z}$ complexity).

\begin{tabular}{c|c|c|c|c|c}
\hline Treatment & $\lambda$ & KS & Dcor & Do & LZ \\
\hline Irrigated sunflower & $0.07 \pm 0.04$ & 0.37 & $2.23 \pm 0.13$ & $1.41 \pm 0.31$ & 0.089 \\
Droughted sunflower & $0.21 \pm 0.05$ & 0.31 & $2.24 \pm 0.21$ & $1.41 \pm 0.03$ & 0.219 \\
Irrigated sugar beet & $0.11 \pm 0.03$ & 0.23 & $2.17 \pm 0.42$ & $1.27 \pm 0.28$ & 0.059 \\
Droughted sugar beet & $0.15 \pm 0.04$ & 0.38 & $2.16 \pm 0.29$ & $1.16 \pm 0.26$ & 0.069
\end{tabular}

\section{DISCUSSION}

Physiological results (Table 1) seemed to be in agreement with water deficit responses commonly found for other plant species, such as decrease in both $\mathrm{g}_{\mathrm{s}}$ and A (Larcher, 1995; Rocha and Moraes,1997; Calbo and Moraes, 1997). Water deficit decreased $55 \%$ of $\mathrm{g}_{\mathrm{s}}$ in sunflower and $69 \%$ in sugar beet, and the $\mathrm{Ci}$ values decreased $17 \%$ in sunflower and $30 \%$ in sugar beet. Net photosynthesis decreased $49 \%$ in sunflower and $41 \%$ in sugar beet (Table 1). This seemed to indicate that the reductions in A were due to both decrease in $g_{s}$ and water stress effect on photosynthetic apparatus, such as a decrease in carboxylation efficiency (Leidi et al., 1993; Calbo and Moraes, 1997). Stomatal conductance might have decreased due to water deficiency in the plant tissues, as indicated by the low water potentials in sunflower $(-2.44 \mathrm{MPa})$ and sugar beet $(-2.25 \mathrm{MPa})$ (Larcher, 1995; Mott et al., 1997).

Results of time series analysis indicated that under both water regimes, $g_{s}$ showed chaotic-like behavior. This suggested that an underlying determinism, rather than an absolute random behavior or a simple homogeneous behavior in the stomatal dynamics in both irrigated and nonirrigated plants, should be the best model for $g_{s}$ dynamics.

Though the low LZ complexity values, these results supported the hypothesis of a complexity dynamics in $g_{s}$ rather than a regular one. Furthermore, LZ values increased in plants under water deficit, mainly sunflower. Once the measurements were taken in controlled environment, and the measurement noise may be considered very low, we could assert that $g_{s}$ behavior was due to plant metabolism dynamics rather than errors in measurements. Considering the period of recovery in this study, although sugar beet plants showed a trend to return to initial levels of $g_{s}$ after the water deficit suspension, the most efficient homeostatic capacity was observed in sunflower plants (Table 1). This indicated higher $\mathrm{g}_{\mathrm{s}}$ stability (in Lyapunov sense, see Fiedler-Ferrara and Prado, 1994) in sunflower than in sugar beet. 

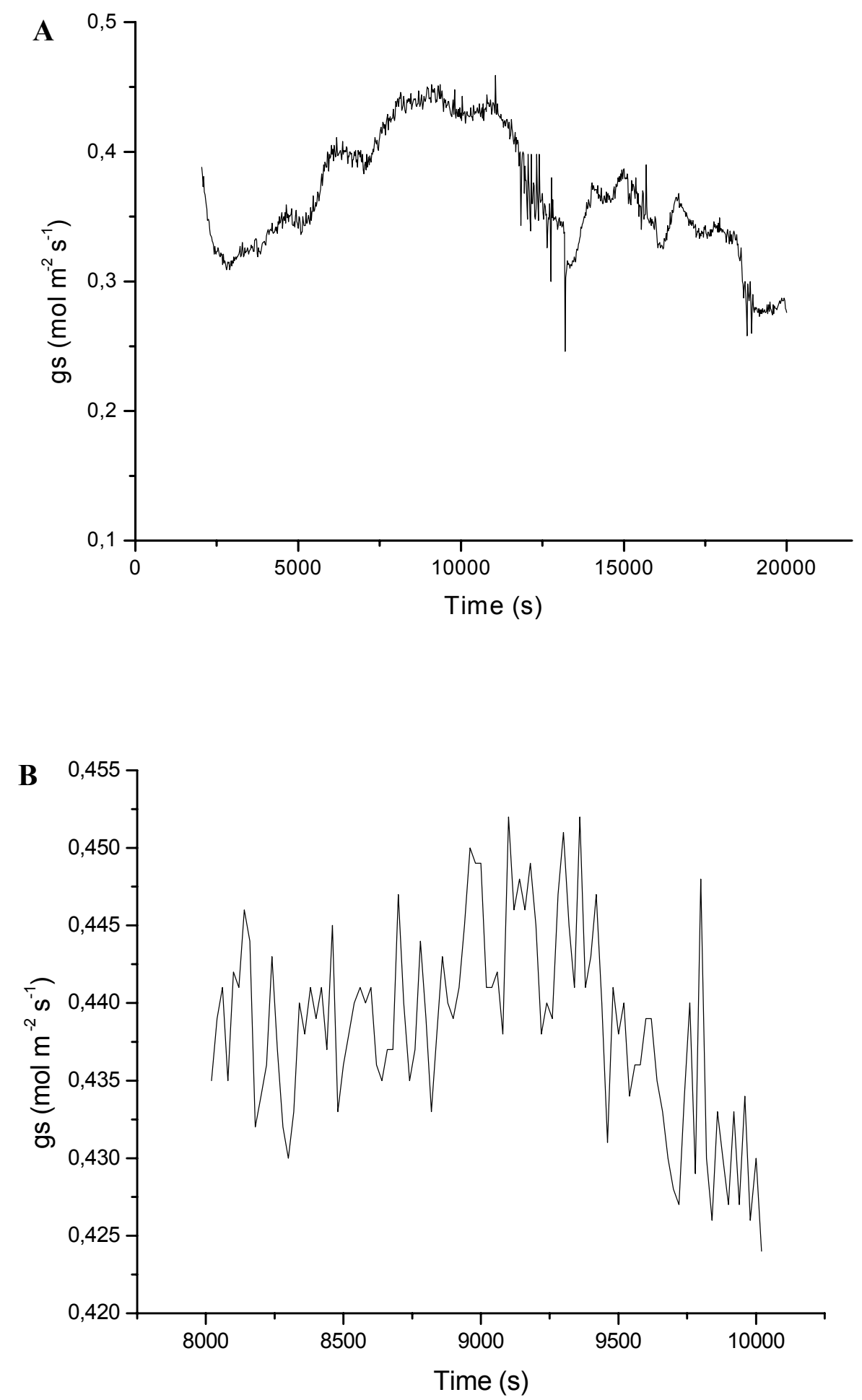

Figure 1 - a) Stomatal conductance time series in sunflower leaf without water deficit. Time interval between the sample points was $20 \mathrm{~s}$. b) Close of the figure 2a to show the internal structure of the temporal dynamics in stomatal conductance. 

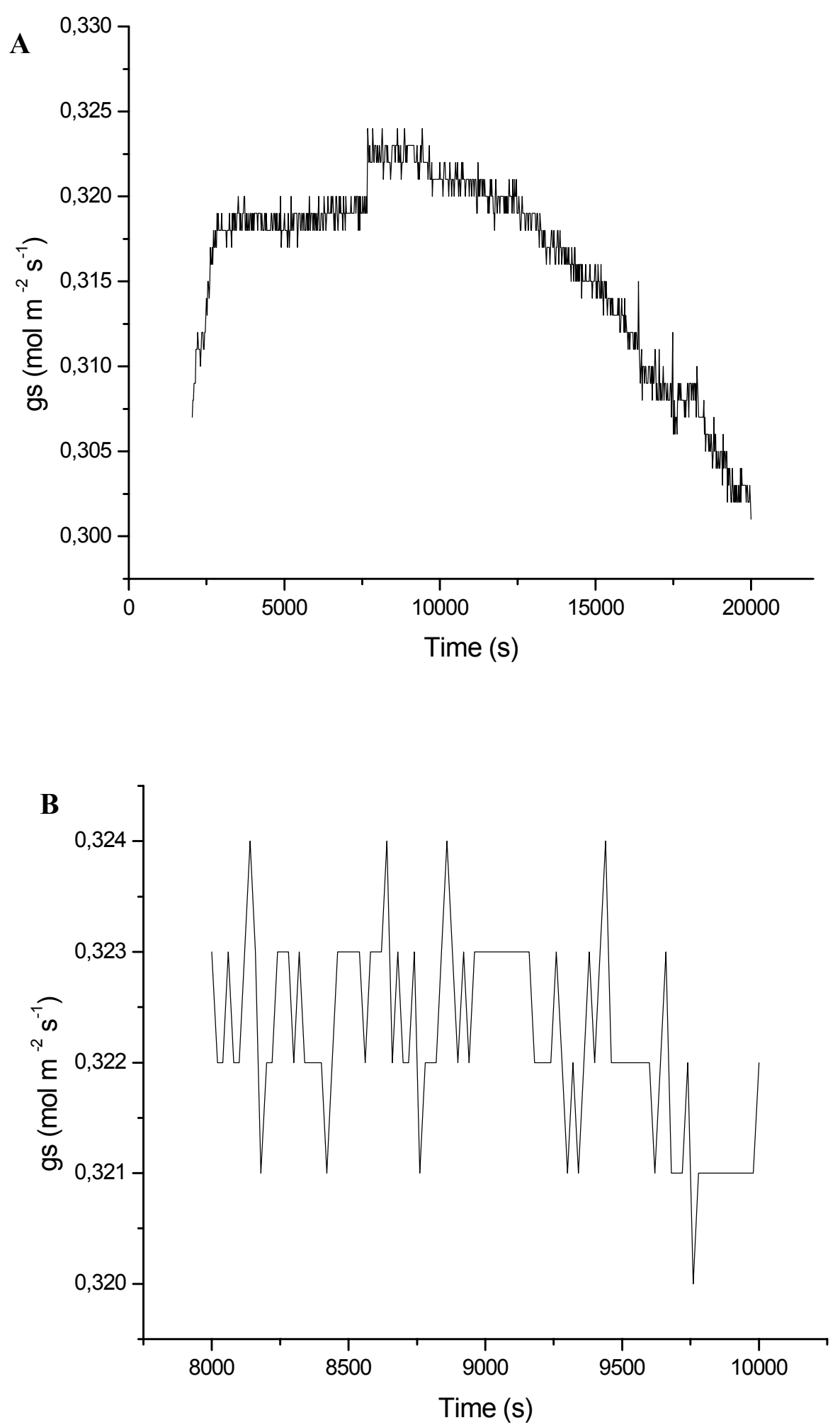

Figure 2 - a) Stomatal conductance time series in sugar beet leaf without water deficit. Time interval between the sample points was $20 \mathrm{~s}$. b) Close of the figure $2 \mathrm{a}$ to show the internal structure of the temporal dynamics in stomatal conductance. 
Sunflower showed more complex dynamics under water deficit than sugar beet, as indicated by LZ and fractal dimensions values (Table 2). This could be an evidence of the hypothesis that plants with complex dynamics were more stable to environmental disturbances.

According to Cardon et al. (1994), Haefner et al. (1997) and Mott et al. (1997) leaf stomata could exhibit temporal and spatial homogeneous behavior or complex spatial and temporal dynamics, depending on environmental and physiological conditions. However, our results seemed to show that independent from water regimes, $g_{s}$ leaf in a determined leaf area showed a complex behavior. This type of dynamics could be related to stomatal heterogeneity at several spatial and temporal scales (Mott and Buckley, 1998). However, well watered plants, where stomatal behavior should be more regular than those in plants under water deficit (Cardon et al., 1994), showed evidences of chaotic-like dynamics in $g_{s}$. This suggested either a constant heterogeneity in gas exchange of leaf stomata, or even a non-linear relation between stomata movements and the $g_{s}$ dynamics. If all leaf stomata achieved the same behavior in a certain period $\mathrm{g}_{\mathrm{s}}$ would probably show a regular dynamics (periodic) in that leaf. This was not observed in our data. Nevertheless, those hypotheses need to be experimentally tested. Some questions could be risen from our results. Why $\mathrm{g}_{\mathrm{s}}$ would be chaotic? What is the biological advantage of that?

According to Møller and Swaddle (1997) the nonlinear dynamics of environment, as well as of biological metabolism, make unlikely that a global stability of a system can be reached. Therefore, it seems reasonable to think that under environmental conditions, which are never actually constant, plants like every other biological system show a non regular metabolism to keep themselves in favorable growth conditions (Erdei et al., 1998). This type of dynamics could be more consistent with the need of adaptation to environmental oscillations (Møller and Swaddle 1997). Indeed, according to Gell-Mann (1996), biological systems can be considered adaptive complex systems. These systems can identify regularities in the environment; retain these information in models; and then, they interact with the real world. However, in each situation there are different competing models and results from action over the environment feedback each model and influence the competition among them.
Shabala et al. (1997) think it is hard to believe that, for plants growing in the natural fluctuating environmental, chaotic responses represent abnormal or damaging behavior, since they have survived for millions of years of evolution in an ever changing environment.

Chaotic dynamics allow organisms some flexibility in responses to environmental changes. This is due to the co-existence of chaotic attractors with many instables periodic orbits. When a chaotic system is disturbed, it may respond remaining chaotic or establishing in its dynamic instable periodic orbits at the border of the chaotic attractor (Møller et al., 1998).

The chaos theory showed that long-term forecast of the state of chaotic system is not possible because of sensibility to initial conditions - SIC (butterfly effect). Any minimal perturbation could lead the system to very different situations because deterministic chaotic systems are highly correlated (Çambel, 1993; Fiedler-Ferrara and Prado, 1994). This mean that, to determine the actual behavior of a dynamic system it is essential to perform a consistent time series analysis with sufficient data points. In this case, a hypothesis about a homogeneous behavior in $\mathrm{g}_{\mathrm{s}}$ could not resist to a more accurate analysis.

Summarizing, the results presented in this report showed that complex dynamics (chaotic-like) might be a common behavior of plant $g_{s}$ under different water conditions. Perhaps, in natural conditions, where the environmental oscillations were higher and more diversified than the experimental conditions in this study, chaos could be the standard situation. Furthermore, complex dynamics could be the most efficient way to maintain plant homeostasis under environmental constrains.

\section{RESUMO}

Este estudo testou a hipótese de que a condutância estomática de uma população de estômatos em uma folha poderia apresentar um comportamento caótico ou complexo sob diferentes condições hídricas, o que poderia favorecer a capacidade homeostática das plantas. A condutância estomática em folhas de girassol e de beterraba cultivadas com irrigação diária e sob deficiência hídrica foi medida com um analisador de gás por infra-vermelho em condições controladas. Os dados foram registrados a cada 20 s durante $6 \mathrm{~h}$. As 
séries temporais obtidas foram analisadas por meio dos coeficientes de Lyapunov, dimensão fractal, entropia KS e complexidade LZ relativa. A condutância estomática nas plantas cultivadas com e sem deficiência hídrica exibiu um comportamento provavelmente caótico. As plantas sob estresse hídrico mostraram uma tendência para um comportamento mais complexo, principalmente as plantas de girassol cuja capacidade homeostática foi superior. Algumas implicações biológicas destes comportamentos são discutidas no texto.

\section{ACKNOWLEDGEMENTS}

This study was supported by FAPESP (Fundação de Amparo à Pesquisa do Estado de São Paulo). The authors would like to thank Raymond S. Pacovsky and Rafael V. Ribeiro for editorial comments, and Waldemar Peres Júnior for language review.

\section{REFERENCES}

Buckley, T. N.; Farquhar, G. D. and Mott, K. A. (1997), Qualitative effects of patchy stomatal conductance distribution features on gas-exchange calculations. Plant Cell Envir., 20, 867-880.

Calbo, M. E. R. and Moraes, J. A. P. V. (1997), Photosynthesis, stomatal conductance, transpiration and osmotic adjustment of buriti plants subjected to water stress. Braz. J. Plant Physiol., 9, 117-123.

Çambel, A. B. (1993), Applied Chaos Theory. Boston : Academic Press.

Cardon, Z. G.; Mott, K. A. and Berry, J. A. (1994), Dynamics of patchy stomatal movements, and their contribution to steady-state and oscillating stomatal conductance calculated using gas-exchange techniques. Plant. Cell. Envir., 17, 995-1007.

Fiedler-Ferrara, N. and Prado, C. C. (1994), Caos: uma introdução. Edgard Blücher, São Paulo.

Erdei, L.; Szeglets, Z.; Barabás, K. N.; Pestenácz, A.; Fülöp, K.; Kalmár, L.; Kovács, A.; Tóth, B. and Dér, A. (1998), Environmental stress and the biological clock in plants: changes of rhythmic behaviour of carbohydrates, antioxidant enzymes and stomatal resistance by salinity. J. Plant Physiol., 152, 265-271.

Gell-Mann, M. (1996), O quark e o jaguar. Rio de Janeiro : Rocco.
Haefner, J. W.; Bunckley, T. N. and Mott, K. A. (1997), A spatially explicit model of patchy stomatal responses to humidity. Plant Cell Envir., 20,1087-1097.

Kauffman, A. S. (1993), The origins of order. New York : Oxford University Press.

Krempasky, J.; Smrcinova, M. and Ballo, P. (1993), Periodicity and chaos in a photosynthetic system. Photosyn. Res., 37, 159-164.

Ksenzhek, O. S. and Volkov, A. G. (1998), Plant energetics. San Diego : Academic Press.

Larcher, W. (1995), Physiological plant ecology. $3^{\text {th }}$ ed. Berlim : Springer-Verlag.

Leidi, E. O.; Lopez, J. M.; Lopez, M. and Gutierrez, J. C. (1993), Searching for tolerance to water stress in cotton genotypes: photosynthesis, stomatal conductance and transpiration. Photosynthetica, 28, 383-390.

Lüttge, U. and Beck, F. (1992), Endogenous rhythms and chaos in crassulacean acid metabolism. Planta, 188, 28-38.

May, R. (1989), The chaotic rhythms of life. New Scientist, 124, 21-25.

McCree, K. J. (1986), Measuring the whole-plant daily carbon balance. Photosynthetica, 20, 82-93.

Møller, A. P. and Swaddle, J. P. (1997), Asymmetry, developmental stability and evolution. Oxford : Oxford University Press.

Møller, A. C.; Hauser, M. J. B. and Olsen, L. F. (1998), Oscilations in peroxidase-catalyzed reactions and their potential function in vivo. Biophys. Chem., 72, 63-72.

Mosekild, E. and Mosekild, L. (1991), Complexity, chaos, and biological evolution. New York : Plenum Press. (Series B: Physics; 270).

Mott, K. A.; Denne, F. and Powell, J. (1997, Interactions among stomata in response to perturbations in humidity. Plant Cell Envir., 20, 1098-1107.

Mott, K. A. and Buckley, T. N. (1998), Stomatal heterogeneity. J. Exper. Bot., 49 : (Special Issue), 407-417.

Pearcy, R. W.; Ehleringer, J.; Mooney, H. A. and Rundel, P. W. (1989), Plant physiological ecology: field methods and instrumentation. New York : Chapman and Hall.

Poon, C. S. and Barahona, M. (2001), Titration of chaos with added noise. Proc. Nat. Ac. Sc., 98, 7107-7112.

Rocha, A. M. S. and Moraes, J. A. P. V. (1997), Influence of water stress on gas exchange in young potted plants of Stryphnodendron adstringens (Mart.) Coville. Braz. J. Plant Physiol., 9, 43-48.

Shabala, S., Delburgo, R. and Newman, I. (1997), Observations of bifurcation and chaos in plant physiological responses to light. Aust. J. Plant Physiol., 24, 91-96. 
Souza, G. M.; Oliveira, R. F. and Cardoso, V. J. M. (2001), Avaliação do ruído em medidas de trocas gasosas feitas em alta freqüência de repetição com analisador de gás por infra vermelho. In: Proceedings of the 8. Congresso Brasileiro de Fisiologia Vegetal. Ilhéus, Bahia, Brazil. pp. 213.

Sprott, J. C. and Rowlands, G. (1995), Chaos Data Analyser: the professional version (PC user's manual). American Institute of Physics, Raleigh.

Takens, F. (1981), Detecting strange attractors in turbulence. In: Rand, D. A. and Young, L. S. (eds.). Dynamical systems and turbulence. Lecture Notes in Mathematics 898. New York : Springer-Verlag.

Terashima, I. (1992), Anatomy of non-uniform photosynthesis. Photosyn. Res., 31, 195-212.

Terashima, I.; Wong, S. C.; Osmond, C. B. and Farquar, G. D. (1988), Characterisation of nonuniform photosynthesis induced by abscisic acid in leaves having different mesophyl anatomies. Plant Cell Physiol., 29, 385-394.

Williams, G. P. (1997), Chaos Theory Tamed. Washington, DC : Joseph Henry Press.

Received: September 20, 2002; Revised: January 31, 2003; Accepted: August 08, 2003. 